\title{
O desempenho de crianças em fase de alfabetização em avaliações de leitura e escrita
}

\author{
Mariana Terra Teixeira \\ Pontifícia Universidade Católica (PUC), Porto Alegre, Rio Grande do Sul, Brasil \\ mariana.terra@acad.pucrs.br \\ Bernardo Kolling Limberger \\ Pontifícia Universidade Católica (PUC), Porto Alegre, Rio Grande do Sul, Brasil \\ bernardo.limberger@acad.pucrs.br \\ Augusto Buchweitz \\ Pontifícia Universidade Católica (PUC), Porto Alegre, Rio Grande do Sul, Brasil \\ augusto.buchweitz@pucrs.br
}

DOI: $\underline{\text { http://dx.doi.org/10.21165/el.v45i2.982 }}$

\begin{abstract}
Resumo
Este artigo aborda o desempenho de crianças em fase de alfabetização em testes de leitura, um eixo do projeto ACERTA. O projeto busca a identificação precoce de transtornos de aprendizagem, mais especificamente, a dislexia. Neste artigo, discutimos os resultados dos testes de leitura e escrita aplicados em escolas de Porto Alegre, os quais auxiliam na identificação de crianças em risco de apresentarem dificuldade inesperada para leitura. Os objetivos específicos deste artigo são: a) verificar o desempenho das crianças em fase de alfabetização em testes de leitura e escrita e b) identificar as dificuldades persistentes que possam ser indicativas de risco de transtorno de aprendizagem. Analisamos os resultados da Provinha Brasil, do ditado ortográfico e da leitura de palavras e pseudopalavras. Os resultados são apresentados a partir de uma perspectiva ainda descritiva da amostra.
\end{abstract}

Palavras-chave: avaliação de leitura; alfabetização; dislexia.

\section{The performance of children learning to read in reading and writing assessments}

\begin{abstract}
This paper is about the performance of children learning to read in reading tests, one of the axes of the project ACERTA (Evaluation of Children at Risk for Learning Disabilities, in Portuguese). The project aims to establish early identification of learning disabilities, more specifically, dyslexia. In this paper, we discuss the results of reading tests made in schools, which help to identify children at risk for the unexpected difficulty learning to read. The specific objectives of this study are: a) to verify the performance of children in literacy stage in reading and writing tests and b) identify the persistent difficulties that may be indicative of learning disorder risk. We analyze, specifically, the results of the tests: Provinha Brasil, spelling test and word/pseudoword reading. The test results are presented with the goal of describing the results from the first years of the project.
\end{abstract}

Keywords : reading assessments; literacy; dyslexia. 


\section{Introdução}

Contribuir para a educação básica brasileira ainda se caracteriza como um desafio para pesquisadores da área da educação e de áreas correlatas, como Linguística Aplicada, Psicologia e Neurociência Cognitiva. Com programas governamentais intensificados no Brasil desde 2002, a universalização do ensino básico, principalmente nas séries inicias, e a alfabetização ${ }^{1}$ da população, atingiram níveis elevados, quase universais (entretanto, dados do IBGE relatam haver ainda 13 milhões de analfabetos no Brasil, sendo o oitavo país do mundo com mais adultos analfabetos $)^{2}$. No entanto, ao quarto ano do ensino fundamental, $59 \%$ das crianças não leem adequadamente para a idade (CASELLA et al., 2011).

As dificuldades com leitura, escrita e matemática nem sempre estão associadas ao método de ensino, por exemplo. Algumas crianças têm dificuldades persistentes que podem ser indicativas de transtorno de aprendizagem. Transtornos de aprendizagem são dificuldades permanentes e inesperadas no aprendizado da leitura e/ou do cálculo. Os transtornos são percebidos em crianças que, apesar da instrução formal e de apresentarem todas as condições típicas para o aprendizado, não conseguem aprender a ler ou a calcular; esses transtornos são denominados, respectivamente, dislexia e discalculia. Focaremos, neste trabalho, na dislexia, que é o transtorno da aprendizagem da leitura.

Primeiramente, devem estar claras as diferenças entre transtornos de aprendizagem (como a discalculia e a dislexia) e dificuldades de aprendizagem. $\mathrm{O}$ transtorno, como mencionado acima, é uma condição permanente. Um disléxico dificilmente conseguirá ler com fluência, ou seja, em velocidade típica para sua idade, ao passo que uma criança com dificuldade de leitura pode ultrapassar essa dificuldade e vir a ler como um leitor típico para a sua idade. O código escrito é artificial, uma invenção cultural; foi criado por volta de 4 a 5 mil anos atrás. Sendo o meio de comunicação escrito algo cultural, quando se começa a aprendizagem da leitura, o cérebro precisa passar por um processo de adaptação de suas redes neuronais para conseguir decodificar o código escrito. A dislexia caracteriza-se pela dificuldade persistente na decodificação das palavras e no desenvolvimento da leitura fluente, especificamente na aprendizagem da relação entre grafema e fonema. Entre os participantes de nossa pesquisa, 60\% das crianças com diagnóstico de dislexia já foram reprovadas pelo menos uma vez. Essas reprovações, em parte, apresentam-se por falta de entendimento do transtorno e de como avaliar e ensinar a criança com dificuldade de ler com fluência.

O objetivo do nosso trabalho é identificar dificuldades persistentes na aprendizagem da leitura nos anos iniciais do processo de alfabetização. Para tanto, apresentamos e discutimos o desempenho de crianças em fase de alfabetização em testes de avaliação de leitura. As crianças que fizeram os testes são de seis escolas públicas do estado do Rio Grande do Sul e participam do projeto guarda-chuva, no qual nosso trabalho está inserido, o projeto ACERTA (Avaliação de Crianças Em Risco de

\footnotetext{
1 Segundo dados do IBGE, ainda parciais, 91,7\% dos brasileiros são alfabetizados: $<$ http://brasilems intese.ibge.gov.br/educacao/taxa-de-analfabetismo-das-pessoas-de-15-anos-oumais.html>.

2 Pesquisa Nacional por Amos tra de Domicílios, PNAD/IBGE, 2014.
} 
Transtornos de Aprendizagem; CAPES/Observatório da Educação) do Instituto do Cérebro do Rio Grande do Sul.

O projeto ACERTA é um estudo longitudinal e investiga, a partir da ressonância magnética funcional (RMF), os marcadores neurais do desenvolvimento da leitura. $\mathrm{O}$ principal objetivo é entender as mudanças que ocorrem no cérebro das crianças quando elas estão aprendendo a ler e, consequentemente, descobrir processos neurobiológicos associados à adaptação cerebral e à leitura. Assim, almeja-se compreender sinais precoces da dislexia. O projeto também tem como meta traçar um panorama da aprendizagem da leitura das crianças brasileiras e, para isso, possui três núcleos de pesquisa em três regiões diferentes do Brasil: o Instituto do Cérebro do Rio Grande do Sul, o Laboratório de Linguagem da Universidade Federal de Santa Catarina e o Instituto do Cérebro da Universidade Federal do Rio Grande do Norte.

O projeto possui três eixos - o eixo clínico $^{3}$, o pedagógico e o computacional - e congrega estudantes e pesquisadores de várias áreas do conhecimento, como Letras, Medicina, Matemática, Fonoaudiologia, Psicologia e Engenharia. O eixo pedagógico do projeto busca avaliar os índices de desempenho escolar de crianças em fase de alfabetização das escolas públicas vinculadas ao projeto. A partir das bases de dados de avaliação escolar do INEP, especificamente, a Provinha Brasil, e da aplicação de testes de leitura e escrita, procura-se delimitar as dificuldades persistentes das crianças na aprendizagem da leitura. Este eixo do projeto ACERTA procura fazer um acompanhamento longitudinal da aprendizagem das crianças das escolas públicas parceiras, com testes de leitura e escrita aplicados às crianças desde que elas estavam no primeiro ano, em 2013, data de início do projeto, até o quinto ano do ensino fundamental, em 2017, ano final do projeto.

O desenlace do projeto pretende ser a identificação precoce, através de biomarcadores e índices de desempenho escolar, de crianças com dificuldades e/ou risco de transtornos de aprendizagem, em conjunto com a construção de um modelo computacional que identifique esse risco. Dessa maneira, o projeto ACERTA busca aliar neurociência e educação e, assim, contribuir para a qualidade do ensino brasileiro.

Este artigo está organizado em cinco partes. $\mathrm{Na}$ segunda seção, nos aprofundamos nos temas aprendizagem da leitura e dislexia, visando ao suporte teórico pertinente aos nossos objetivos; na terceira seção, explicamos o método de nossa pesquisa, descrevendo os testes de leitura utilizados com as crianças; na quarta seção, expomos a análise dos resultados obtidos; e, por fim, na última seção, apresentamos nossas considerações sobre o desempenho das crianças nos testes de leitura, e as dificuldades persistentes e passageiras na fase de alfabetização que podem ser indicativas do transtorno de aprendizagem da leitura, a dislexia.

\section{Aprendizagem e avaliação da leitura}

As crianças adquirem a língua falada espontaneamente, por meio de um processo de aquisição que não exige instrução, somente exposição. Por outro lado, a aprendizagem da leitura não ocorre breve e espontaneamente (MORAIS, 2013), ela implica a aprendizagem de um conjunto complexo de operações de representações

\footnotetext{
${ }^{3}$ Para uma descrição mais aprofundada sobre o eixo clínico do projeto, o ambulatório de aprendizagem, desenvolvido no ambiente do Hospital São Lucas da PUCRS, veja Costa et al. (2015).
} 
gráficas em representações fonológicas e semânticas que cria uma interface visual para a língua. O modo mais eficaz para a aprendizagem da leitura é a compreensão do princípio alfabético (MORAIS; KOLINSKY, 2015), o que requer a tomada de consciência dos fonemas, a sua associação às letras e aos grafemas e o desenvolvimento das habilidades para operar mentalmente com representações fonêmicas e, de maneira geral, fonológicas. Depois disso, a criança pode desenvolver a habilidade de decodificação, que alicerça uma leitura autônoma e fluente que, por sua vez, alicerçam o desenvolvimento da compreensão leitora.

$\mathrm{O}$ processo de aprendizagem da leitura resulta em mudanças no funcionamento do cérebro do aprendiz. Um modelo desse processo, ainda usado atualmente, é o de Frith (1985). Segundo tal modelo, a aprendizagem da leitura acontece em três etapas principais. $\mathrm{Na}$ fase pictórica/logográfica, a criança compreende palavras familiares, devido a traços gráficos salientes, que agem como pistas para ativar a memória. A ordem das letras é ignorada pela criança, pois ela memorizou a sua forma visual, e os traços fonológicos são secundários. É como o reconhecimento de um objeto visual. $\mathrm{Na}$ fase alfabética, a criança consolida o conhecimento da correspondência grafemafonema, ou seja, a decodificação das letras individualmente. A ordem das letras e os fatores fonológicos desempenham um papel maior, porque não há mais o tratamento global da palavra. Por fim, na fase ortográfica, ocorre a identificação visual das palavras como um todo. As unidades ortográficas passam as ser os morfemas ou sequências de letras. Nesse estágio, a leitura está automatizada, a consciência fonêmica está desenvolvida, a criança lê com fluência. No entanto, esses estágios não são estanques, porque continuamente a criança transita por eles devido à aquisição de novas palavras. Dehaene (2012) denomina esta transformação que precisa acontecer no cérebro como dependente de um processo de reciclagem neuronal ${ }^{4}$. Uma região associativa do cérebro, na junção entre o lobo occipital e o lobo temporal do leitor aprendiz se especializa de forma crescente: na aprendizagem e, de forma progressiva, emerge uma especialização em direção ao hemisfério esquerdo, e esta região associativa chama-se a área da forma visual das palavras (DEHAENE, 2012).

Para que as crianças consigam ter sucesso na aprendizagem da leitura, é imprescindível o desenvolvimento da consciência fonêmica (DEHAENE, 2012; MORAIS, 2013). A consciência fonêmica, habilidade de manipular e contrastar na memória os fonemas e os grafemas correspondentes (HOOVER, 2002), está inserida em um âmbito maior, ou seja, na consciência fonológica - um conhecimento explícito das unidades e das propriedades fonológicas da língua (MORAIS, 2013). A consciência fonológica abrange a consciência das unidades maiores da fonologia da língua, como a prosódia, a sílaba, a rima, bem como das unidades menores (do fonema - consciência fonêmica).

A avaliação da aprendizagem da leitura pode ser feita por meio de tarefas que simulam partes do processo de aprendizagem. O processo de aprendizagem da leitura não consiste apenas na decodificação. É preciso desenvolver a leitura e os processos cognitivos superiores de compreensão (por exemplo, inferenciação e construção de ideias principais). Então, as avaliações da aprendizagem da leitura precisam dar conta

\footnotetext{
${ }^{4}$ Segundo Dehaene (2012, p. 166), reciclagem neuronal consiste na "invasão parcial ou total de territórios corticais inicialmente destinados a uma função diferente, por um objeto cultural novo. [...] A reciclagem neuronal é uma reconversão: ela transforma uma função que, antes, tinha sua utilidade em nosso passado evolutivo, numa função nova mais útil no contexto cultural presente".
} 
também desses processos, não somente da decodificação. Como neste estudo analisamos o desempenho de crianças do segundo ano do ensino fundamental em testes de leitura e escrita, os testes utilizados avaliam o desenvolvimento de processos básicos da aprendizagem da leitura. Tratamos, neste trabalho, de avaliações de leitura que dão conta dos seguintes processos: conversão grafema-fonema, regras contextuais simples, regras contextuais complexas e irregularidades da língua.

Os testes de avaliação da leitura contemplam, muitas vezes, a análise de "erros", entendidos aqui como parte do processo de aprendizagem da leitura e da escrita. Segundo Moojen (2009), a análise de erros e acertos dos alunos é imprescindível para o entendimento dos processos linguísticos subjacentes e para $o$ planejamento de estratégias de ensino. Há erros que são esperados para a faixa etária; por isso, é necessário que o professor e/ou o clínico tenham conhecimento para identificar possíveis crianças que tenham algum padrão desviante dessa expectativa. Esses erros podem ser analisados no âmbito da (1) conversão grafema-fonema, pois podem ocorrer substituições, omissões, adições, transposições ou inversões de letras; (2) das regras contextuais simples, no qual pode haver alguma falta de consideração ou conhecimento da existência de determinadas regras que definem o valor do grafema no contexto; (3) regras contextuais complexas, que envolvem basicamente acentuação e (4) irregularidades da língua, que consistem em arbitrariedades na ortografia, sobretudo das constantes do português brasileiros (por exemplo, palavras com a letra ' $x$ ", 'exato', 'xícara', 'excelente' e 'táxi'), que envolvem uma automatização mais complexa.

Outra forma de avaliar a leitura é por meio da leitura de pseudopalavras. Segundo Salles e Parente (2007), a combinação de fonemas ou grafemas que não existem no léxico de uma língua mostram a aprendizagem das regras fonológicas, e o desenvolvimento da rota fonológica, a via de processamento que subjaz a decodificação dos grafemas (associação entre imagem visual e imagem acústica). Essa via de processamento é também chamada de rota dorsal. Por outro lado, a automatização da leitura e a leitura de palavras irregulares dependem da via lexical (esta conhecida como ventral, no cérebro), que recupera desde o início a palavra e seu significado e depois utiliza as informações para recuperar a pronúncia (ARAÚJO, 2011; DEHAENE, 2012). Nas palavras irregulares, a leitura por rota fonológica tende a regularizá-las, gerando uma pronúncia incorreta e conflituosa com relação àquela associada com 0 processamento pela rota lexical (SALLES; PARENTE, 2007).

\subsection{Dislexia: o que é, suas bases neurais}

Para crianças com dislexia o processo de aprendizagem da leitura é árduo. Os leitores disléxicos possuem uma dificuldade na manipulação mental dos fonemas (DEHAENE, 2012). Tunmer e Greaney (2010) definem a dislexia com relação a quatro componentes: (1) dificuldades persistentes de aprendizagem da alfabetização; (2) crianças com desenvolvimento típico, sem outros transtornos; (3) exposição de alta qualidade, baseada em instrução e intervenção; (4) transtorno nas habilidades de processamento fonológico necessárias para aprender a ler e escrever. Ao definir dislexia dessa maneira, os autores não sugerem que as crianças diagnosticadas não podem aprender a ler, mas que elas precisam de instrução mais intensiva e de longa duração.

Estudos sobre as bases neurais da leitura na dislexia têm demonstrado que a dificuldade dos disléxicos em associar grafema e fonema tem relação com uma ruptura no sistema de análise fonológica da palavra, na região parietotemporal do córtex 
(principalmente no giro angular) tanto em adultos quanto em crianças (SHAYWITZ, S. E. et al., 1998; SHAYWITZ, B. A. et al., 2002; DEHAENE, 2012). Como descrito acima, esta região compõe a rota fonológica. Além disso, os disléxicos mostram hipoativação da região occípito-temporal esquerda, especificamente, a área visual da forma das palavras, para leitura (DEHAENE, 2012); a ativação desta região está associada com o desenvolvimento da leitura fluente, sendo um marcador neural para tal e uma região que em nada ativa em adultos que não aprenderam a ler, por exemplo. Como compensação para o déficit, os disléxicos possuem níveis de ativação maiores em regiões frontais, inclusive do hemisfério direito; há também um aumento relativo na ativação de regiões associadas com processos atencionais. Em geral, os resultados indicam que as rotas esperadas não se formam (ou seja, o cérebro não "aprende" o caminho que tipicamente se aprende) e há mais energia despendida com processos atencionais.

\section{Método}

Este trabalho faz parte do projeto ACERTA $^{5}$, especificamente, do eixo pedagógico do projeto. Os participantes do estudo descrito neste artigo, em específico, são crianças de 7 e 8 anos dos segundos anos do ensino fundamental de seis escolas públicas de Porto Alegre. Cento e vinte crianças, cujos pais autorizaram a participar do projeto, fizeram os testes de leitura e escrita que serão descritos a seguir. Essas crianças estavam cursando o primeiro ano, em 2013, na primeira coleta e aplicação de testes de leitura do projeto ACERTA, e o segundo ano, em 2014. Aqui, apresentaremos os resultados dos testes aplicados às crianças em 2014.

\subsection{Tarefas de leitura e escrita}

As tarefas de leitura e escrita do projeto ACERTA são aplicadas todo ano, para verificar o desenvolvimento na aprendizagem da leitura das crianças com o passar do ano escolar. A bateria de testes aplicada pela equipe do projeto ACERTA consiste em seis tarefas: Provinha Brasil (INEP, 2013), Ditado ortográfico (MOOJEN, 2009), Avaliação da leitura de palavras e pseudopalavras (SALLES, 2005), Avaliação da fluência e legibilidade da escrita (SARAIVA; MOOJEN; MUNARSKI, 2007), Produção textual (SALLES, 2005) e Avaliação da fluência e compreensão leitora (SARAIVA; MOOJEN; MUNARSKI, 2007). Neste artigo, focalizamos as três primeiras.

\subsubsection{Provinha Brasil}

O primeiro teste de leitura e escrita que analisaremos neste artigo é a Provinha Brasil (INEP, 2013). A Provinha Brasil ${ }^{6}$ é uma avaliação obrigatória e é aplicada pelas próprias escolas. É um teste do Ministério da Educação aplicado, preferencialmente, aos

\footnotetext{
5 O projeto de pesquisa foi aprovado pelo Comitê de Ética em Pesquisa da PUCRS com o número certificado de apresentação para apreciação ética (CAAE) 30895614.5.0000.5336.

6 Todos os alunos dos segundos anos das seis escolas fizeram a Provinha Brasil, devido ao caráter obrigatório desta avaliação, de acordo com as normas do Ministério da Educação; no entanto, tivemos acesso somente às avaliações das 120 crianças cujos pais assinaram o termo de consentimento livre e esclarecido do projeto ACERTA.
} 
alunos do segundo ano do ensino fundamental das escolas públicas de todo o Brasil. O objetivo desse teste é a avaliação da educação escolar na alfabetização das crianças.

A Provinha Brasil contém 20 questões $^{7}$ que são referentes aos conhecimentos que se espera que os alunos tenham adquirido após o início do processo de alfabetização. Esta avaliação foi aplicada pelo próprio professor da turma. Como veremos nos resultados, os níveis das questões variam em grau de dificuldade e avaliam desde a decodificação, com o reconhecimento de letras e palavras (analisando o início do processo de leitura), até processos cognitivos superiores, como o reconhecimento do assunto de um pequeno parágrafo e a inferência de informação através da relação entre partes (analisando um nível avançado no processo de leitura, a compreensão). Na seção dos resultados, veremos que o desempenho das crianças muda de acordo com a dificuldade do processo de leitura exigido pela questão.

\subsubsection{Leitura de palavras e pseudopalavras (SALLES, 2005)}

O segundo teste que utilizamos como instrumento para avaliação do desenvolvimento da leitura em crianças em fase de alfabetização é um teste de leitura de palavras e pseudopalavras do português brasileiro (SALLES, 2005). O teste consiste na leitura de 60 itens: 40 palavras (20 regulares, 20 irregulares), como 'sapo', 'saxofone', 'indivíduo'; e 20 pseudopalavras, como 'zure', 'azercico', 'paresta'. A instrução dada às crianças era que elas lessem em voz alta para que o pesquisador pudesse ouvi-las. Elas também foram instruídas a ler da forma mais correta e mais rápida que conseguissem. $\mathrm{O}$ pesquisador salientava para a criança que havia palavras conhecidas e palavras inventadas, que elas não conheciam. As palavras eram escritas em caixa alta e dadas às crianças, separadamente, em três colunas, com 20 palavras em cada coluna. Diferente da Provinha Brasil, aplicada pelo professor ao mesmo tempo a toda turma, o teste era aplicado por um colaborador do projeto ACERTA e era feito com uma criança de cada vez, em uma sala separada na própria escola da criança e com controle de tempo.

O teste de avaliação da leitura de palavras e pseudopalavras de Salles (2005) tem palavras com distintos níveis de dificuldade e procura avaliar diferentes habilidades exigidas pela leitura. Há palavras regulares do português brasileiro e relativamente simples, com duas sílabas, como 'sapo'; para lê-las, a criança precisa fazer a conversão grafema-fonema. Há palavras que, para serem lidas corretamente, exigem que a criança saiba regras contextuais simples como 'garganta'; e há palavras que possuem irregularidades da língua, como o uso do "s" e seus diferentes sons em português brasileiro, como a palavra 'casa'. Este teste não avaliava processos cognitivos superiores envolvidos na aprendizagem da leitura, mas, sim, processos de conversão grafema-fonema, aprendizagem de regras contextuais $\mathrm{e}$ irregularidades da língua portuguesa. Como foi aplicado ao segundo ano do ensino fundamental, era esperado que as crianças de 7 e 8 anos tivessem mais facilidade com palavras regulares e de construção silábica simples.

\subsubsection{Ditado ortográfico (MOOJEN, 2009)}

O ditado balanceado (MOOJEN, 2009) apresenta 50 palavras, distribuídas de acordo com a frequência de uso das letras no vocabulário da língua portuguesa. Foram

\footnotetext{
${ }^{7}$ Edições da Provinha Brasil podem ser podem ser obtidas no site do INEP (Instituto Nacional de Estudos e Pesquisas Educacionais Anísio Teixeira), <http://provinhabrasil.inep.gov.br/kit-teste/2015>.
} 
ditadas para as crianças palavras isoladas (25 em cada dia de coleta), que são contextualizadas quando necessário (por exemplo, com auxílio da sentença completa, "As crianças brincam"). Por meio de um único ditado, é possível verificar o desempenho das crianças em palavras com grafemas regulares (por exemplo, 'favor', 'galo') e irregulares ('reflexo', 'horror' e 'choca'), além do uso de regras contextuais da escrita ('causa', 'bisavô' e 'incêndio'). Salientamos que utilizamos este ditado para avaliar a escrita e a leitura, por consideramos esses processos altamente interdependentes entre si.

O procedimento de aplicação do ditado ocorreu da seguinte forma: os pesquisadores distribuíram uma folha padronizada às crianças e solicitaram que as crianças utilizassem somente lápis. O pesquisador responsável ditava cada palavra em voz clara e alta e a repetia uma vez segundos após. As palavras foram ditadas respeitando a variedade dialetal falada na cidade (por exemplo, com a elevação da átona final em "galü").

\section{Resultados e discussão}

Nesta seção, apresentamos os resultados dos três testes descritos. Esses testes buscavam analisar se pelo menos os processos iniciais de aprendizagem da leitura estavam consolidados nas crianças dessas seis escolas públicas ao final do segundo ano. De acordo com o desempenho das crianças nos testes de leitura e escrita, pretendemos identificar as dificuldades persistentes na aprendizagem da leitura. A análise dos resultados apresentados é uma análise ainda preliminar da população investigada.

\subsection{Provinha Brasil (2014)}

As 10 primeiras questões da Provinha Brasil avaliam processos fundamentais da leitura, como a relação entre som e grafia, o reconhecimento de letras e silabas e a leitura de palavras. As 10 últimas questões avaliam processos mais complexos, de localização da informação, reconhecimento do assunto e inferência de informação. Os resultados desta avaliação demonstram que as crianças tiveram uma média de acertos maior nas 10 primeiras questões. Dessa forma, a dificuldade dos alunos nas últimas questões da Provinha Brasil indica que as crianças do segundo ano já são, em média, capazes de decodificar, mas ainda têm dificuldade para fazer a leitura fluente de um texto. Isso é, em parte, esperado, já que as crianças estão aprendendo a ler e ainda não têm a leitura automatizada. No entanto, quando observamos que as crianças também tiveram dificuldades em questões de leitura de frases simples podemos ver que as habilidades de leitura delas estão ainda em nível bastante preliminar para o segundo ano do ensino fundamental. Há, ainda, outro detalhe, a Provinha Brasil, em geral, não teve seu tempo de aplicação padronizado. Salienta-se que variações em alguns minutos no tempo de aplicação podem mascarar aprendizagem de leitura que permite ao aluno acertar, mas que ainda estaria tipicamente lenta. A variável tempo, portanto, deve ser sempre levada em conta. Acurácia sem a avaliação de tempo pode mascarar um processo de leitura ainda lento.

Aumentando a especificidade da análise, podemos perceber dados escondidos pelas médias. As médias para os processos fundamentais de reconhecimento da relação sonoro-gráfica e da decodificação são altas. No entanto, a análise da média de acertos geral das crianças nas 20 questões da Provinha Brasil e do desvio padrão dessa média 
revelam que algumas crianças tiveram um desempenho abaixo do esperado. A média de acertos foi de 14,7 questões e o desvio padrão foi de 2,3 questões. A disparidade entre a média de acerto das crianças é relativamente alta, pode representar crianças que acertaram $85 \%$ da prova e crianças que acertaram $62 \%$ da prova. 13 crianças ficaram três desvios padrão abaixo da média, ou seja, acertaram no máximo oito questões, 39\% da Provinha. Essas crianças correspondem a quase 10,83\% da amostra total e podem representar uma população escolar que precisa ser acompanhada com mais atenção para risco de transtorno de aprendizagem. Nota-se que essa porcentagem parece ir ao encontro da literatura sobre o transtorno da aprendizagem da leitura, a dislexia, que afeta, em média, de $5 \%$ a $20 \%$ da população escolar (SHAYWITZ, 2006).

Com o número alto de acertos nas primeiras questões da Provinha, referentes à decodificação, percebe-se que muitas crianças, no segundo ano do ensino fundamental, já se encontram na fase alfabética de aprendizagem da leitura, e estão consolidando o conhecimento da correspondência grafema-fonema, ou já o tem consolidado. Entretanto, as 13 crianças que ficaram três desvios padrão abaixo da média de acertos podem estar em risco de dificuldade ou transtorno de aprendizagem, pois ainda demonstram dificuldade no processo de decodificação e pouca consciência fonêmica, o que não é esperado para a faixa-etária (de 7 e 8 anos de idade). Como vimos, estudos sobre as bases neurais da leitura na dislexia têm demonstrado que a dificuldade dos disléxicos está na associação grafema-fonema, o que tem relação com uma ruptura no sistema de análise fonológica da palavra, na região temporoparietal do córtex (principalmente no giro angular). A identificação precoce do risco e da dificuldade na decodificação fonológica é importante para uma intervenção correta e em tempo (ou seja, precoce), uma instrução mais intensiva sobre os fonemas e sons da língua. Assim, é possível evitar a reprovação escolar desnecessária de crianças.

\subsection{Leitura de palavras e pseudopalavras (SALLES, 2005)}

A avaliação do teste de leitura de palavras e pseudopalavras de Salles (2005) foi feita pelos membros do projeto ACERTA, orientados pelas fonoaudiólogas do projeto. Conforme também realizado em Salles (2005), os erros de leitura foram contabilizados em seu total e divididos em erros na leitura de palavras regulares, erros na leitura de palavras irregulares e erros na leitura de pseudopalavras. Salientamos que os erros são considerados como parte do processo de aprendizagem da leitura e são tomados, aqui, como diagnóstico do desempenho das crianças do segundo ano nas habilidades de leitura e escrita. Podemos ver, no gráfico abaixo, a quantidade de erros de cada tipo.

Gráfico 1 - Erros na leitura de palavras e pseudopalavras no teste de leitura de Salles (2005)

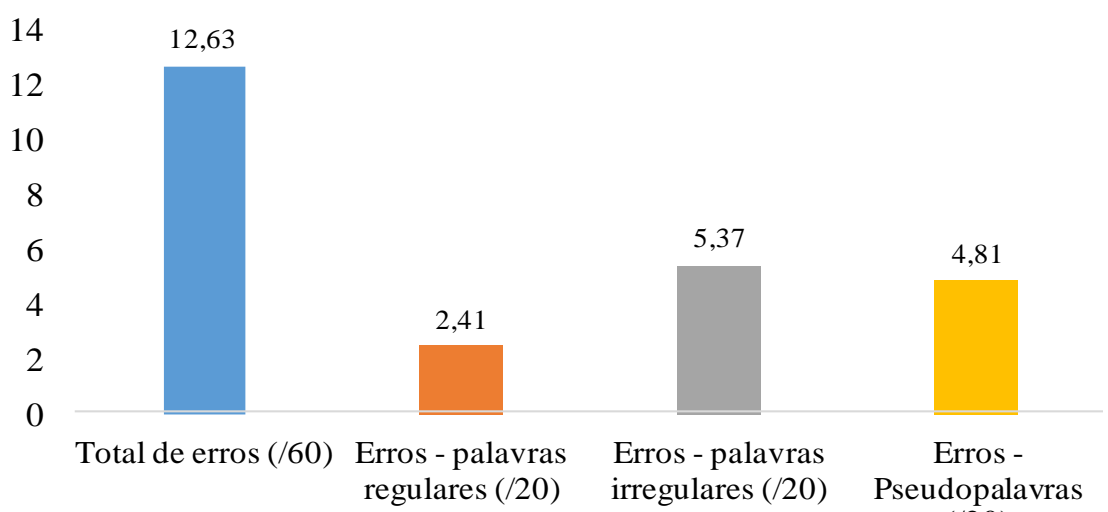

(/20) 
O gráfico mostra que os erros mais cometidos pelos alunos foram em relação à leitura de palavras irregulares da língua. Isso representa uma leitura ainda não automatizada. As crianças parecem estar ainda na fase da decodificação, lendo através da rota fonológica. A utilização da rota lexical, da recordação da palavra como um todo, ainda está em segundo plano na aprendizagem da leitura. Palavras irregulares demandam mais da rota lexical, através da qual memorizamos a forma de algumas palavras. O segundo maior número de erros é na leitura de pseudopalavras, esses erros indicam dificuldades na decodificação, como são palavras inventadas, a criança precisa fazer a relação grafema-fonema de cada letra e cada sílaba para ler. As crianças cometeram menos erros nas palavras regulares, conforme o esperado, já que são mais familiares para as crianças e também regulares. 12,63 foi a média do total de erros cometidos pelas crianças na leitura das 60 palavras e pseudopalavras do teste de leitura de Salles (2005).

Nesta tarefa, também se avaliou a velocidade da leitura, para isso, mede-se o tempo que cada criança levava para ler as 60 palavras da lista. O tempo representa a fluência e a fluidez da leitura, uma habilidade alcançada já em um estágio mais avançado de aprendizagem da leitura, quando a decodificação está consolidada. Como comentado acima, o tempo é uma variável que tem de ser considerada com relação à acurácia. Quanto mais rápido a criança lê, mais automatizada está a leitura dessa criança. No entanto, a maioria das crianças do segundo ano demonstrou estar ainda em um estágio mais preliminar, de decodificação, no qual a leitura é lenta e ainda incorreta com pseudopalavras. Aqui, nossa análise reside também na grande variação de tempos de leitura, o que demonstra um aprendizado inconsistente da leitura nas escolas; houve crianças com uma velocidade que demonstra já certa fluidez e crianças que ainda demoraram para efetuar a leitura. A média de velocidade de leitura das 60 palavras foi de 188,2 segundos, porém, o desvio padrão foi de 138,8 segundos. O número alto do desvio padrão representa a discrepância entre alunos que já decodificam as palavras e pseudopalavras com fluidez e alunos que ainda estão aprendendo a consolidar este processo básico da aprendizagem da leitura. Há muita variabilidade nos resultados, o que indica a não uniformidade no sucesso do ensino da leitura nas escolas públicas brasileiras $^{8}$. Como vimos, a velocidade da leitura pode ser um indicador de risco de transtorno de aprendizagem. Aqui, o acompanhamento longitudinal feito pelo projeto ACERTA é importante, pois crianças com dificuldade de leitura podem vir a ler em velocidade considerada normal para a idade, mas as crianças disléxicas, possivelmente, continuarão a ler em uma velocidade mais baixa do que a média referente à sua idade $\mathrm{e}$ escolaridade. Crianças com dois desvios padrão acima na velocidade de leitura neste teste de leitura de palavras e pseudopalavras foram convidadas a fazer o exame de ressonância magnética funcional. Os dados preliminares e resultados das imagens cerebrais são descritos na seção "4.4 Relação dos dados descritivos com os dados de neuroimagem".

\footnotetext{
${ }^{8}$ Não há padronização no método de ensino para a aprendizagem da leitura nas escolas brasileiras. Piper (2015) analisa os métodos utilizados nessas mesmas seis escolas públicas de Porto Alegre que participam do projeto ACERTA. A autora indica que as escolas que utilizam o método fonológico em detrimento do método global têm maiores índices de sucesso no ensino da leitura.
} 


\subsection{Ditado ortográfico (MOOJEN, 2009)}

Depois da correção do ditado pelos membros do projeto ACERTA, os erros foram quantificados de acordo com a sugestão de Moojen (2009). Às vezes, as crianças

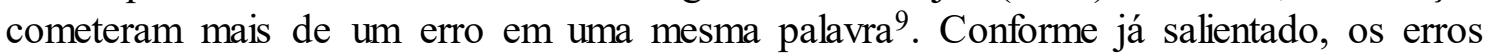
são considerados, aqui, como parte do processo e como diagnóstico do desempenho das crianças na leitura e na escrita. O gráfico abaixo apresenta a descrição dos resultados, considerando a quantidade total de erros no ditado.

Gráfico 2 - Resultados do ditado ortográfico de Moojen (2009)

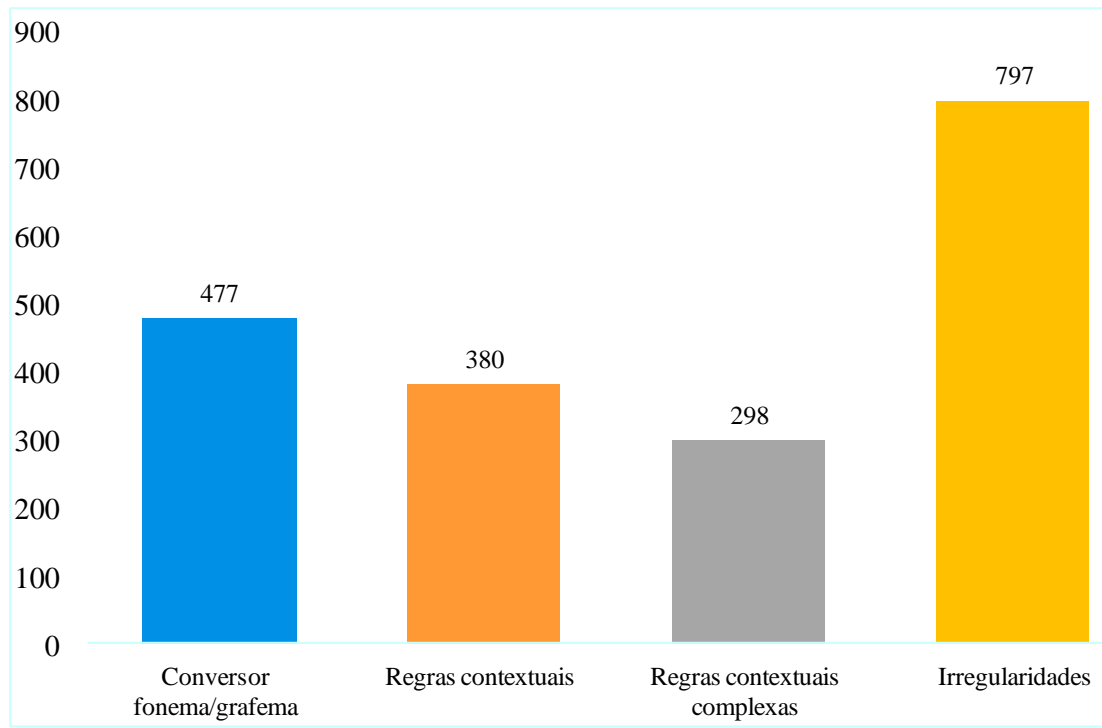

A maior parte de erros ocorreu nas irregularidades (total: 797). Inseridas nessa categoria está o uso das letras ' $x$ ', 'j/g', 'ç', 's' e 'c', 'h', 'lh' e 'ch'. Quando estão nas palavras, esses grafemas são, por vezes, opacos na língua portuguesa. Trata-se de irregularidades específicas da escrita da língua portuguesa. Nessa categoria, as crianças escreveram, por exemplo, 'insêndio' ao invés de 'incêndio', 'esperiencia' ao invés de 'experiência', 'nacer', ao invés de 'nascer', 'orror', ao invés de 'horror'. Muitas vezes, como as crianças leem as palavras irregulares pela rota fonológica, elas tendem a regularizá-las, não colocando a letra 'h", por exemplo (SALLES; PARENTE, 2007).

A segunda categoria na qual as crianças mais cometeram erros é a de conversor fonema/grafema (total: 477). Os erros classificados nessa categoria são, por exemplo, erros de substituição de consoante surda por sonora (e vice-versa), omissão e adição de letras, substituição aleatória de letras, inversão de letras e transposição de letras na palavra. São ocorrências que refletem a dificuldade específica na decodificação e na consciência fonêmica. As crianças escreveram, por exemplo, 'fagão' ao invés de 'vagão', 'calo' ao invés de 'galo'. Outros exemplos de erros nessa categoria são de omissão de letras, por exemplo, em 'códgo' ao invés de 'código', e adição de letras, como em 'açúcare' ao invés de 'açúcar'. Erros bastante frequentes nessa categoria

\footnotetext{
9 Um exemplo é a escrita da palavra 'experiência'. Algumas crianças escreveram, por exemplo 'esperiencia'. Neste caso, cometeram dois erros: um pela troca da letra " $x$ " por "s" e o outro pelo esquecimento do acento circunflexo. $\mathrm{O}$ primeiro erro foi classificado como erro de irregularidade, e o segundo como erro de regras contextuais complexas (acentuação).
} 
foram também de substituição aleatória: as crianças substituíram, por exemplo, 'bispo' por 'bisco", 'gente' por 'zente'.

Nas categorias de regras contextuais, se contabilizadas separadamente, houve menos erros, em comparação com as demais. No entanto, se somarmos as duas categorias, atingimos 678 erros. $\mathrm{Na}$ categoria regras contextuais simples se encaixa o uso dos 'rr' e dos 'ss', o uso do 'qu' e do 'gu', o ' $\mathrm{n}$ ' em trava de sílaba, as vogais e ditongos nasalizados (por exemplo, o uso de 'ão' e 'ã'). Nesse caso, as crianças escreveram palavras como 'horor', 'exenplo', 'guorro', 'brincan' e 'manha'. Na categoria regras contextuais complexas se encaixam os erros relacionados à acentuação (omissão, adição e troca de acento). As crianças cometeram erros como 'taxi', 'exercíto' e 'séxo'. Diante disso, é notório que a maior parte das dificuldades das crianças está associada com as irregularidades, arbitrariedades da ortografia do português (MOOJEN, 2009), por envolverem mais exercício para a consequente automatização. Podemos verificar que, no segundo ano dedicado à alfabetização, a leitura ainda não está automatizada. No fim do segundo ano, nem todas as crianças das escolas participantes do estudo estão alfabetizadas ${ }^{10}$. No entanto, muitas crianças já compreenderam o princípio alfabético (MORAIS; KOLINSKY, 2015) e já alcançaram a fase alfabética (FRITH, 1985), pois já conseguem decodificar e apresentam, por isso, menos erros no conversor grafema-fonema.

A habilidade de decodificar tem relação com o desenvolvimento da consciência fonêmica. Portanto, a hipótese para aquelas crianças que tiveram muitos erros no conversor grafema-fonema pode ser a falta de desenvolvimento pleno dessa consciência. Talvez essas crianças não tenham tido muitas oportunidades de desenvolvimento das consciências fonológica e fonêmica em casa ou na escola, o que é possibilitado por meio de jogos de rima, de adição e omissão de fones, trava-línguas, parlendas, poemas, entre outras. Isso significa também que as crianças que tiveram dificuldade na decodificação começaram a aprender a ler somente na escola, pois o desenvolvimento da consciência fonêmica é inerente à aprendizagem da leitura de um sistema alfabético.

\subsection{Relação dos dados descritivos com os dados de neuroimagem}

A avaliação total das crianças feita pelo projeto ACERTA consiste em seis testes, aqui focalizamos apenas três. Posteriormente aos testes de leitura e escrita feitos nas escolas, as crianças que demonstraram dificuldade (medida pelo número de erros ou pelo desvio padrão) foram avaliadas pelo eixo clínico do projeto, no ambulatório de aprendizagem, participaram da anamnese e dos testes neuropsicológicos. Em seguida, as crianças foram encaminhadas para um exame de ressonância magnética funcional, outro eixo fundamental do projeto ACERTA. Buchweitz et al. (2014) apresentaram resultados preliminares desses exames (Figura 1). As imagens foram geradas enquanto 10 crianças participantes do estudo faziam uma tarefa de leitura de palavras e pseudopalavras.

\footnotetext{
10 De acordo com a lei $n^{\circ} 12.801$ (BRASIL, 2013), todas as crianças devem estar alfabetizadas até os 8 (oito) anos de idade ou ao final do $3^{\circ}$ ano do ensino fundamental da educação básica pública. Lei disponível em <http://www.planalto.gov.br/CCIVIL_03/_Ato2011-2014/2013/Lei/L12801.htm>.
} 
Dificuldade de leitura

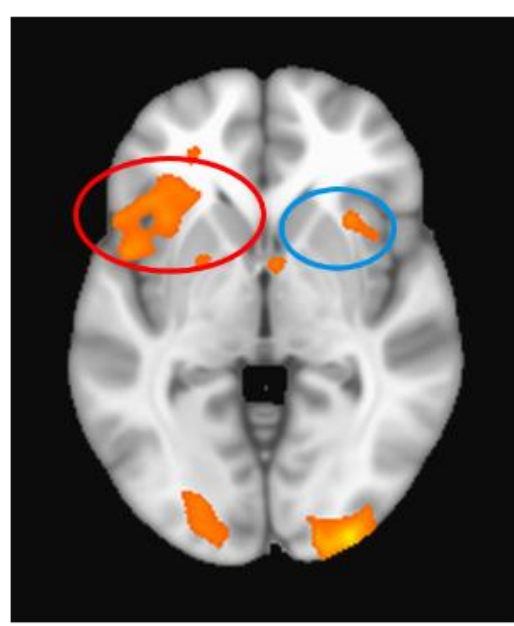

Dislexia

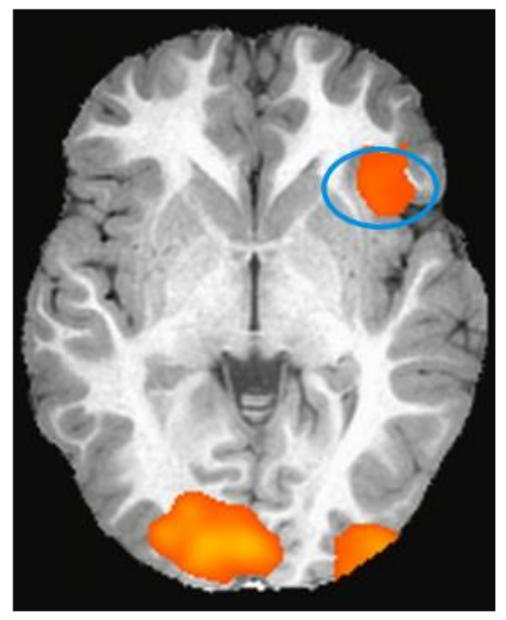

Figura 1 - Padrões de ativação cerebral de crianças do projeto ACERTA.

Fonte: Buchweitz et al. (2014)

Os resultados demonstram (1) ativação no giro angular esquerdo para a leitura de palavras > pseudopalavras; (2) ativação nos giros frontais inferiores esquerdo e direito para todas as palavras (palavras + pseudopalavras) $>$ descanso. Apesar de os resultados preliminares ainda não terem sido comparados a um grupo controle (não disléxicos), há um indicativo precoce de um padrão de ativação cerebral que é característico para os disléxicos (hipoativação da região temporoparietal para a leitura de pseudopalavras e spillover de ativação para o córtex frontal direito). A compensação é maior para os participantes disléxicos, porque os participantes com dificuldades de leitura têm a ativação no córtex frontal (região responsável também pela articulação, segundo Shaywitz, 2002). Os resultados de Buchweitz et al. (2014) corroboram os achados de Shaywitz et al. (1998, 2002) e Dehaene (2012). A hipoativação na região occípito-temporal esquerda, encontrada nos estudos de Shaywitz não foi encontrada neste estudo preliminar, porque não foi realizada ainda a comparação com o grupo controle.

\section{Considerações Finais}

O primeiro objetivo deste artigo foi apresentar e discutir o desempenho das crianças em fase de alfabetização em testes de leitura e escrita. Esse desempenho apresentou-se bastante variável entre as crianças, uma vez que o conjunto das crianças apresentou erros em pontos diversificados nas tarefas e altos desvios-padrão. No entanto, há "erros" padrões nas tarefas, como, por exemplo, dificuldades maiores nas últimas questões da Provinha Brasil (que envolvem compreensão de texto). Esse resultado demonstra que as crianças do segundo ano já são, em média, capazes de decodificar, mas ainda têm dificuldade para fazer a leitura fluente de um texto, o que é, de certa forma, um resultado esperado para estas turmas. A leitura automatizada demanda tempo de instrução e experiência para ocorrer. Somente com a fluidez na leitura as crianças conseguirão compreender textos e inferir informações. 
Outro padrão identificado no desempenho das crianças nos três testes de leitura e escrita descritos neste trabalho é a dificuldade na leitura e na escrita de palavras irregulares. Os resultados da tarefa de leitura de palavras e pseudopalavras demonstraram, inclusive, que as crianças tiveram mais facilidade na leitura de pseudopalavras em comparação com as palavras irregulares, menos comuns na faixa etária das crianças. Isso pode ser explicado pela fase da aprendizagem da leitura em que parecem se encontrar as crianças aqui analisadas. As crianças dos segundos anos, entre 7 e 8 anos, que fizeram os três testes de leitura e escrita aqui descritos parecem estar na fase alfabética de desenvolvimento da leitura. Somente no último estágio da aprendizagem da leitura, a fase ortográfica, há a identificação visual das palavras como um todo. Dessa maneira, as crianças não têm ainda as representações ortográficas das palavras irregulares consolidadas na memória de longo prazo e, por isso, cometem erros recorrentes na leitura e escrita de palavras irregulares.

O segundo objetivo deste artigo foi identificar sinais que podem indicar dificuldades persistentes indicativas de risco de transtorno de aprendizagem. Em cada uma das três tarefas, existem, ainda no segundo ano, erros que envolvem déficit fonológico ou a imaturidade da consciência fonêmica. Esses erros podem ser identificados, sobretudo, nas tarefas que envolvem decodificação, como erros na leitura de palavras e pseudopalavras (SALLES, 2005), no conversor grafema-fonema (MOOJEN, 2009) ou na relação sonora-gráfica (INEP, 2013). Caso uma criança tenha muitos erros em todas essas tarefas, pode ser que ela esteja em risco de dislexia. São essas crianças que são chamadas para exames no ambulatório de aprendizagem, eixo clínico do projeto, e, confirmada a hipótese, para um exame de ressonância magnética funcional. Diante disso, os próximos passos do eixo pedagógico do projeto ACERTA são a realização da nova coleta de dados e a correção dos testes. Ainda, a análise conjunta dos dados dos núcleos de Florianópolis e de Natal também constitui um passo futuro para o eixo pedagógico do projeto ACERTA.

Acreditamos que projetos como o ACERTA devem ser incentivados porque são imprescindíveis para o aprimoramento das metodologias de ensino. Além disto, os transtornos de aprendizagem não diminuem ao longo da vida escolar e suas consequências tendem a perdurar por toda idade adulta. A identificação e intervenção precoces desses transtornos podem evitar reprovações escolares e ajudar crianças disléxicas a superar a barreira neurobiológica da aprendizagem da leitura.

\section{REFERÊNCIAS}

ARAÚJO, A. Aprendizagem infantil: uma abordagem da neurociência, economia e psicologia cognitiva. Rio de Janeiro: Academia Brasileira de Ciências, 2011. 246 p.

BUCHWEITZ, A. et al. Neural correlates of dyslexia and poor reading: a multicenter study on early indices of reading disability and difficulty. PINHEIRO; Â. M. V.; VILHENA, D. de A. (Eds.). II World Dyslexia Forum. Anais do II World Dyslexia Forum. Belo Horizonte: Faculdade de Filosofia e Ciências Humanas, 2014. p. 71.

CASELlA, E. B.; AMARO JR., E.; DA COSTA, J. C. As bases neurobiológicas da aprendizagem da leitura. In: ARAÚJO, A. (Ed.). Aprendizagem infantil: uma abordagem da neurociência, economia e psicologia cognitiva. Rio de Janeiro: Academia Brasileira de Ciências, 2011. p. 37-78. 
COSTA, A. C. et al. Ambulatório de Aprendizagem do Projeto ACERTA (Avaliação de Crianças Em Risco de Transtorno de Aprendizagem): métodos e resultados em dois anos. In: SALLES, J. F.; HAASE, V. G.; MALLOY-DINIZ, L. (Eds.). Neuropsicologia do Desenvolvimento: infância e adolescência. Porto Alegre: Artmed, 2015. p. 151-158.

DEHAENE, S. Os neurônios da leitura: como a ciência explica a nossa capacidade de ler. Tradução de Leonor Scliar-Cabral. Porto Alegre: Editora Penso, 2012. 374 p.

FRITH, U. Beneath the surface of developmental dyslexia. Surface dyslexia, v. 120121, p. 301-330, 1985.

HOOVER, W. The Importance of Phonemic Awareness in Learning to Read. SEDL Letter, v. XIV, n. 3, p. 9-12, 2002.

INEP. Provinha Brasil - avaliando a educação. Caderno do aluno Leitura, teste 1. Ministério da Educação - Brasil, 2013. 23 p.

MOOJEN, S. Avaliação do desempenho alfabético-ortográfico: ditado balanceado. In: $103.182 \mathrm{p}$. . A escrita ortográfica na escola e na clínica. Casa do Psicólogo, 2009. p. 77-

MORAIS, J. Criar leitores - para professores e educadores. Barueri: Minha editora, 2013.

MORAIS, J.; KOLINSKY, R. Psicolinguística e leitura. In: MAIA, M. (Ed.). Psicolinguística, Psicolinguísticas. São Paulo: Editora Contexto, 2015. p. 129-142.

PIPER, F. K. A influência do método de ensino para a aprendizagem de leitura. 2015. 103 f. Dissertação (Mestrado em Letras) - Pontifícia Universidade Católica do Rio Grande do Sul, Porto Alegre, 2015.

SALLES, J. F. Habilidades e Dificuldades de Leitura e Escrita em Crianças de $2^{a}$ Série: Abordagem Neuropsicológica Cognitiva. 2005. 307 f. Tese (Doutorado) Instituto de Psicologia, Universidade Federal do Rio Grande do Sul, Porto Alegre.

SALLES, J. F. de; PARENTE, M. A. D. M. P. Avaliação da leitura e escrita de palavras em crianças de $2^{\text {a }}$ série: abordagem neuropsicológica cognitiva. Psicologia: Reflexão e Crítica, v. 20, n. 2, p. 220-228, 2007.

SARAIVA, R; MOOJEN, S; MUNARSKI, R. Avaliação da Compreensão Leitora: Textos expositivos. São Paulo: Casa do Psicólogo, 2007. 104 p.

SHAYWITZ, S. E. et al. Functional disruption in the organization of the brain for reading in dyslexia. Proceedings of the National Academy of Sciences, v. 95, n. 5, p. 2636-2641, 3 mar. 1998.

SHAYWITZ, B. A. et al. Disruption of Posterior Brain Systems for Reading in Children with Developmental Dyslexia. Society of Biological Psychiatry, v. 3223, n. 02, p. 101$110,2002$.

SHAYWITZ, S. Entendendo a dislexia: um novo e completo programa para todos os níveis de problemas de leitura. Tradução de Vinicius Figueira. Porto Alegre: Editora Artmed, 2006. 288 p.

TUNMER, W.; GREANEY, K. Defining Dyslexia. Journal of Learning Disabilities, v. 43, n. 3, p. 229-243, 1 maio 2010. 
Recebido em: 05/03/2015

Aprovado em: 26/04/2016 